\title{
El més enllà en sant Vicent Ferrer, Francesc Eiximenis i sor Isabel de Villena. Els llimbs dels patriarques
}

\section{The afterlife accordling saint Vicent Ferrer, Francesc Eiximenis and sor Isabel de Villena. The limbo of patriarchs}

\author{
Albert Toldrà I Vilardell \\ albert.toldra@uv.es \\ Universitat de València
}

\begin{abstract}
Resum: Els llimbs dels patriarques o sina d'Abraham és un espai del més enllà amb tarannà vestibular, on van a raure els personatges de l'antic Testament abans de la redempció. Crist hi davalla quan mor, els rescata i clausura aquest espai. En la tradició textual i iconogràfica catalana, mentre Crist és als llimbs mostra als patriarques el seu propi cos encara a la creu i tots plegats visiten Maria.
\end{abstract}

Paraules clau: Llimbs dels patriarques, infern, sant Vicent Ferrer, Francesc Eiximenis, Isabel de Villena.

\begin{abstract}
The limbo of patriachs or Sine of Abraham is a space of the afterlife with vestibular disposition, where the personages of the old Testament wait before redemption. Christ goes down when dies, rescues them and closes this space. In the Catalan textual and iconographic tradition, while Christ is in limbo, he shows the patriarchs his own body still on the cross, and all together visit Mary.
\end{abstract}

Keywords: Limbo, hell, saint Vicent Ferrer, Francesc Eiximenis, Isabel de Villena.

\footnotetext{
* Aquest treball s'emmarca en el projecte d'investigació «Biografías marginales: violencia, sexo, género e identidad. Edición y análisis de fuentes documentales valencianas de la Época Foral» (PGC2018-097011-B-I00) del Ministerio de Ciencia, Innovación y Universidades del Gobierno de España.
} 
Albert Toldrà i Vilardell. El més enllà en sant Vicent Ferrer, Francesc Eiximenis i sor Isabel de Villena. Els llimbs dels patriarques

Ens centrarem en un espai concret del més enllà, un espai habitualment menystingut o poc estudiat, els llimbs dels patriarques, també coneguts com sina d'Abraham. Com sabem, el concepte medieval d'infern comprén tot un conjunt, un sistema d'espais superposats segons l'esquema ptolemaic: «Axí com en una poma són moltes casetes, axí en lo cor de la terra són moltes concaves», diu sant Vicent ${ }^{1}$. Espais independents, amb diverses funcions i diferents combinacions de la pena física o de sentit, ja que la pena espiritual o de dany opera en tots l'àmbit inferior, i de les dues durades, temporal o eterna. És a dir, i de dalt a baix: els llimbs dels patriarques, únicament amb pena de dany temporal, el purgatori, amb pena de dany i de sentit temporals, els llimbs dels infants, també només amb pena de dany però eterna, per als que únicament tenen el pecat original, i l'infern inferior, amb totes dues penes eternes.

Aquesta compartimentació ja és establerta al s. XIII; Eiximenis (1992: 55), al Libre dels Àngels, ens enumera les «habitacions» subterrànies:

\begin{abstract}
En la primera estaven los sants pares ans que Jhesuchrist vingués ne ls trasqués (...) La segona pus baxa ves imfern és purgatori. La terça abitaçió (...) pus baxa és dels imfants qui són morts sens babtisme. La quarta e pus baxa que tota és la abitaçió dels dolents qui Déus à maleÿts de perpetual maledicçió.
\end{abstract}

Sant Vicent (Ferrer 1975, VI: 147) anomena els espais lochs, carçres o cases; per ordre ascendent:

\begin{abstract}
En la una és infern dels dapnats, ple de foch actiu, pudent, escur, ardén, e aquí estan les ànimes impenidens. Altra casa hi ha aprés, pus alta, e és dels infants no bategats. No y ha foch ni dyables ne tuments, mas tenebres, que no senten la glòria (...) En la III ${ }^{a}$ casa pus alta és purgatori, plena de foch actiu, clar, que la pena que done és intol lerable. L'altra casa és Limbus primum; ara buyda és, que 1 dia de la resurrecció los ne tregué Jesuchrist.
\end{abstract}

L'origen d'aquest espai infernal és l'al lusió bíblica de la paràbola de Llàtzer, qui hi és dut pels àngels (Lc 16, 19-31). La referència és molt confusa: Abraham hi intervé alhora com a persona i la seua sina com a lloc on reposa Llàtzer. Aquesta, amb la resta de referències bíbliques que enviaven als inferns -el Xeol indiferenciat jueu- la totalitat dels morts, facilità la formació dels llimbs dels patriarques com a espai dins el complex infernal. Segons Amat, des del segle IV el cristianisme busca espais intermitjos, vestibulars, entre el cel i l'infern, llocs de refrigerium per als non valde boni i els non valde mali, en espera de la retribució definitiva. Altres espais amb aquest caràcter seran el paradís terrenal i el purgatori (Amat 1985: 391). La sina d'Abraham és esmentada també d'una manera equívoca al segle $\mathrm{V}$ per sant Agustí (2009, IX: 3), i ja nítidament definida per sant Tomàs (S. Th. 3 , q. 52, a. 2; Supl., q. 69 , a. 4) com a lloc d'espera anterior a la redempció.

1 Ferrer 1975, III: 126. Una versió llatina de l'analogia, en Ferrer 2002, 132: «Nam terra est sicut una mançana in terra quam sum plures cellule et habet istas quatuor celluelas, scilicet carcer dapnatorum, ubi accedunt omnes infideles et inpenitentes, et linbum parvulorum, ubi accedunt innocentes decedentes sine babtismo et etiam filii parvuli infidelium, et locus purgatorum, ubi accedunt illi qui non fecerunt suficientem penitenciam (...) et sinus perfectorum, ubi accedebant ante Adventum Christis.

SCRIPTA, Revista internacional de literatura i cultura medieval i moderna, núm. 14/ desembre 2019/ pp. 175 - 188 ISSN: 2340-4841 · doi:10.7203/SCRIPTA.14.16364 
Albert Toldrà i Vilardell. El més enllà en sant Vicent Ferrer, Francesc Eiximenis i sor Isabel de Villena. Els llimbs dels patriarques

El tret essencial dels lllimbs dels patriarques, doncs, és l'espera, el tarannà vestibular; ${ }^{2}$ sant Vicent arriba a comparar-los amb l'espera cortesana al despertar reial: «expectabant in pulcra sala». ${ }^{3}$ Tancats els cels des de l'expulsió d'Adam i Eva, ningú no hi podia entrar, i les ànimes dels personatges de l'Antic Testament rebotaven de la porta del cel cap als llimbs, sense excepció, enfasitza el predicador:

\begin{abstract}
que ans de Jesuchrist, totes les ànimes, santes e males, anaven a infern, e no podien entrar en paraís (...) Adam, quan morí, e Noé morí, a infern anaren llurs ànimes, no en lo infern dels dapnats, mas en hun altre loch, que no y havie dyables ne turments, e ha nom limbus. Los altres qui eren peccadors anaven baix a l'infern dels diables (...) Més vos diré de sent Johan Babtista, que ere molt sant (...) Mas quan morí (...) a infern ne anà ab los altres sants, e no pogueren entrar en paradís fins que Jesuchrist se’n pugà al cel ab ells lo jorn de la sua Ascensió (Ferrer 1975, III: 203; 2009: f.79r.).
\end{abstract}

No hi ha turments, ni foc ni dimonis, només la pena de dany o absència de Déu. S'assemblen als altres llimbs, els dels infants; però a diferència d'aquests altres, són provisionals; en paraules de sant Vicent (Ferrer 1975, V: 166; també en 1975, IV: 141; V: 37 i 2002: 54): «han gran claredat de la gràcia de Déu, mas no claredat de glòria; e totes les ànimes que eren allí, totes ne isqueren quan Jesuchrist resuscità». És un espai, com veurem, freqüentat pels àngels, que hi van a consolar $\mathrm{i}$ informar els seus habitants.

El gran esdeveniment dels llimbs és el rescat dels patriarques per Crist en el transcurs de la catàbasi o davallament infernal, una volta mort i durant els tres dies que hi roman -de divendres a diumenge de Pasqua. El viatge de Crist a l'infern, tot i que no s'esmenta als evangelis i és a penes suggerit al Nou Testament només en unes vagues al lusions de sant Pau (Rom, 10, 6) i dels Actes dels Apòstols (Act 2, 24), és doctrinal, i es considera real, no simbòlic4. Tanmateix, a les professio fidei del cristianisme primitiu el davallament no s'esmenta; ${ }^{5}$ no serà fins al s. XIII que s'afirme taxativament; sant Tomàs diu que Crist visita tots els espais infernals. ${ }^{6}$

\footnotetext{
2 L'Enciclopedia Cattolica el defineix així (Enciclopedia... 1948, VII: veu Limbo): «Stato e luogo, in cui si trovarono i giusti del Vecchio Testamento, i quali, pur uscendo da questa vita in grazia e pienamente purificati dalle loro colpe, non potevano entrare in Paradiso, perché la Redenzione dell'umanità non era stata compiuta».
}

3 Ferrer 2002: 666: «sicut milites sperant regem in sala pulcra quando ipse rex surgat de dormicione (...) ita sancti patres non stabant in inferno, neque in purgatorio, neque in loco parvulorum, sed expectabant in pulcra sala, scilicet linbo vel sinu Abrae, ubi non sunt demones nec ignis»

4 S. Th. 3, q. 52. Enciclopedia... 1948: discesa; Bot 2002: 39). I a Ferrer 1995: 360: «Unde doctrina est Theologorum certa, et vera, quod quando Iesus fuit mortuus pro nostra salvacione, et corpus fuit sepultum in monumento, ad idem anima descendit ad Limbum inferni pro extrahendis animabus Sanctorum Patrum, et tantum quantum stetit in monumento, ad idem anima in Inferno, et cum exiit de Inferno, et corpus de sepulcro, gloriosum, ressucitatum».

5 Enchiridion... 1973: 260, 237, 131. El concili de Sens (1140), entre els «errors» de Pere Abelard, en condemna la tesi $\mathrm{n}^{\circ}$ 18: «Quod anima Christiper se non descendit ad inferos, sed perpotentiam tantum». I el segle següent, el concili de Letrà IV (1215), al seu capítol primer, De fide catholica, afirma taxativament: «descendit ad infernos, resurrexit a mortius et ascendit in caelum».

6 S. Th. 3, q. 52, a. 6. «Christo descendente ad inferos, omnes qui erant in quacumque parte inferni, sunt aliqualiter visitati». 
Albert Toldrà i Vilardell. El més enllà en sant Vicent Ferrer, Francesc Eiximenis i sor Isabel de

Villena. Els llimbs dels patriarques

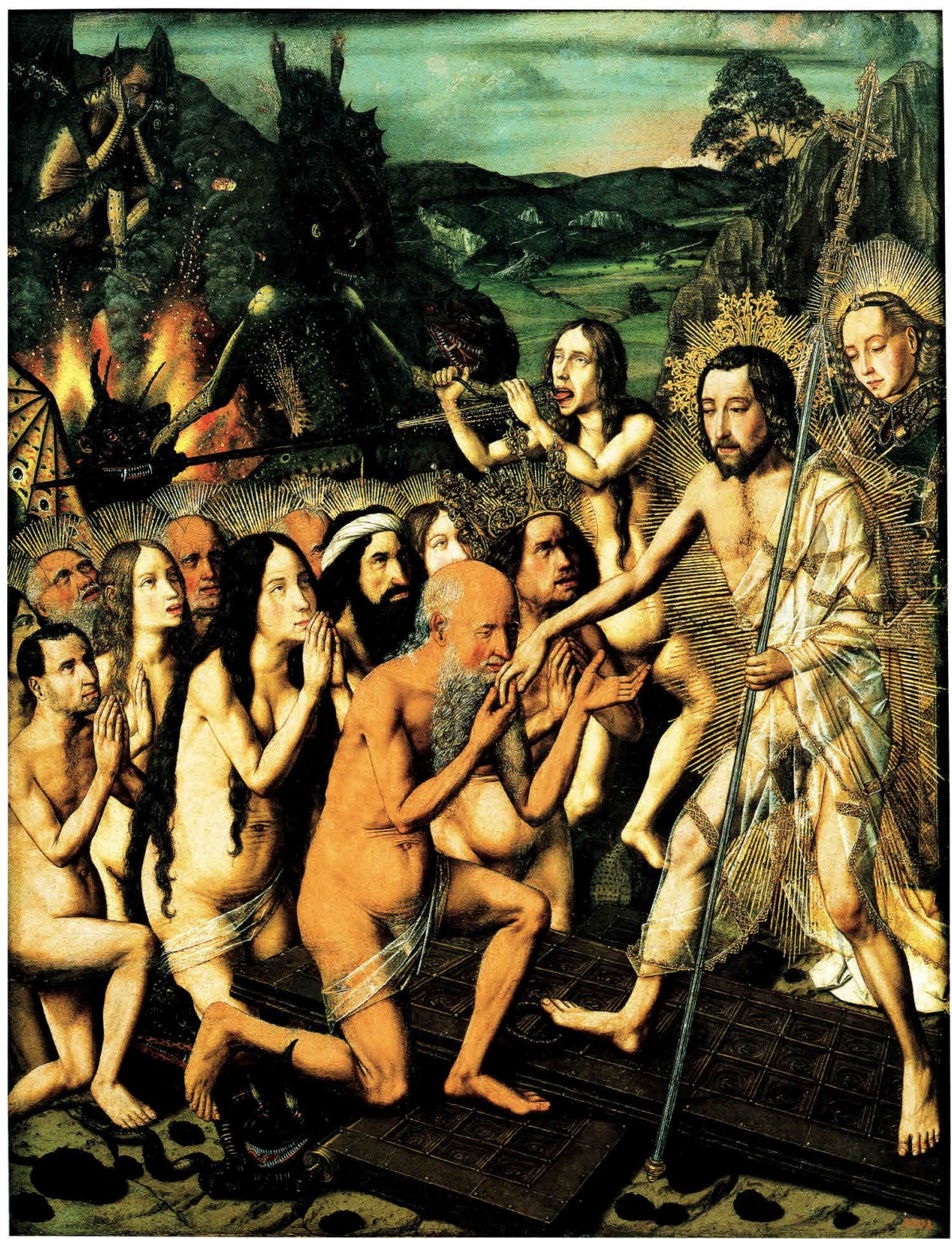

Bartolomé Bermejo, Davallament de Crist als llimbs (1475). Barcelona, MNAC.

L'entrada del Salvador a l'infern i el trobament amb els patriarques suposa la unió simbòlica de l'Antic i el Nou Testament, la derogació de l'antiga llei i la promulgació de la nova, i enceta una nova etapa per a la humanitat. No és un mite específicament cristià: el victoriós davallament de l'heroi solar -Osiris, Orfeu, Herakles, Mitra- al regne inferior, referent a la periodicitat de la fecunditat seria, segons Durand, arquetípic. ${ }^{7}$ Les religions agràries són sotèriques: el déu principal mor i

7 Durand 1963: 321: «Le scénario de ce drame est essentiellement constitué par la mise à mort et la résurrection d'un personnage

SCRIPTA, Revista internacional de literatura i cultura medieval i moderna, núm. 14/ desembre $2019 /$ pp. 175 - 188 ISSN: 2340-4841 · doi:10.7203/SCRIPTA.14.16364 
resuscita, davallament que simbolitza el cicle de l'etern retorn anual; aquest substrat pagà precristià hauria estat ben arrelat a l'imperi romà (Eliade 1999: 117; Maldonado 2003: 34; Bologne 1993: 200).

La catàbasi ja venia prefigurada a l'Antic Testament per David derrotant Goliat i Sansó el lleó, i per l'estada de Jonàs a la panxa de la balena; i a més havia estat anunciada pels profetes (Os 12, 14; Phil 2,10), així com el rescat dels patriarques (Zach 9, 11; Col 2, 15). Per tant, els habitants dels llimbs -entre els quals eren els profetes mateixos- coneixien el que havia de passar, però en trobarem en l'àmbit català fins a quatre versions diferents.

En la primera, és l'ànima de sant Joan Baptista la precursora que informa els presoners de l'encarnació de Crist; és la versió que presenta la Legenda aurea (Vorágine 1982: 34), seguida per Llull (1981: 27), tots dos del segle XIII, en què l'especialització funcional dels espais de l'infern encara no s'han bastit completament; per això tots dos parlen de turments:

\begin{abstract}
tots los profetes e ls sants qui eren ans del aveniment de Jhesu Christ (...) anaven en infern per rahó del original peccat. On, com plach al Fill de Déu que fo encarnat e nat, Sant Johan Baptista fo missatgé del Fill de Déu als sants qui eren en les penes infernals turmentats, e denuncià a aquells l'aveniment del Fill de Déu, del qual foren los sants alegres e consolats.
\end{abstract}

La segona forma de presentar els fets, seguida per diferents autors medievals com ara sant Vicent als seus sermons, és un desenvolupament del primer argument: els patriarques van assabentant-se a poc a poc de la proximitat de la salvació, gràcies als nouvinguts. L'arribada dels innocents els informa de l'encarnació de Crist; l'escena de la irrupció dels xiquets al trist asil dels ancians, que ens relata el predicador (Ferrer 1975, VI: 212), és particularment surrealista:

\footnotetext{
quan dintre hun dia tants fadrinets partiren de aquest món, sens fe, trobaren aquí los sants pares Adam, Matusalem, Noè e altres, etc. Estaven aquí sperant quan vindrie Jesuchrist, e quan veheren aquí tanta minyonalla, meravellaren-se molt (...) quan dins hun dia ne veren venir tants e interrogaren-los: «E de hon veniu?» «Nosaltres sapiats que som venguts del món, que hun rey, Herodes, per ço com sap que Jesuchrist és nat, ha mort a nosaltres, e ell és romàs, fugit en Egipte». «Oo, donchs, ja és nat lo Salvador nostre?» Digueren aquests: «Hoc».
}

La tercera versió, en què els habitants dels llimbs són informats pels àngels, és la seguida per Eiximenis (1992, V: 7) al Libre dels àngels: sant Miquel revela l'esdevenidor al seu gran amic Adam, ja expulsat del paradís.

E li revelà lo temps de la sua mort, e com devallaria en lo lim dels pares, e que ell lo y acompanyaria ab los seus sants àngels axí com a car amich de Déu e seu; e com aquí trobaria la ànima del seu car fill Abel (...) ab los altres sants pares (...) esperant la preciosa ànima e mort del Salvador qui ls en trauria e ls portaria tots a la Glòria.

mythique, la plupart du temps divin, à la fois fils et amant de la déesse lune». 
Albert Toldrà i Vilardell. El més enllà en sant Vicent Ferrer, Francesc Eiximenis i sor Isabel de Villena. Els llimbs dels patriarques

I finalment una variant d'aquesta trama, la del Vita Christi de sor Isabel de Villena (1497: XI), més complexa i heterodoxa, en què es presenta l'encarnació de Crist com a resultat del prec d'Adam a Déu: «lo venerable pare Adam, recordà's que ja eren passats cinc mília anys de la sua creació e que, per sa pròpria culpa, ell e los fills seus estaven d'aquell temps ençà en tan dura captivitat (...) Per què Adam e los que ab ell eren tingueren consell dins los llimbs on se trobaven».

Tots plegats prenen la decisió de demanar que Déu «done fi a l'exili nostre». Acceptada la petició i encarnat ja Jesucrist dins de Maria, la divinitat disposa que els patriaques tancats als llimbs prenguen cossos materials per visitar-la, «cossos segons sa natura», en un avenç de la posterior visita arran la resurrecció. En aquesta primera trobada, amb un aire cortesà, Maria s'alça del braç de sant Miquel, i Adam vol besar-li la mà, «e sa mercè no la y volgué donar, perquè li era pare; ans lo féu levar e abraçà’l ab molta amor, e prenint-lo per la mà, tornàs a seure en la cadira». Després la saluda Eva: «levant-se sa senyoria ab una singular familiaritat e amor abraçant-la e besant-la, dix-li «Bé siau venguda, mare mia e de tota humana natura»» (Villena 1497: LIX-LX).

Els llimbs són una presó: «los catius de la casa dolorosa de aquest carçre (...) los quals seen en tenebres e ombra de mort» (Villena 1497: CLIV), i en un altre lloc, «en tan dura captivitat, acompanyats de tantes dolors e misèries (...) en aquest lloc de tenebres on no hi ha consolació nenguna ni repòs» (Villena 1497: XI). L’abadessa descriu llur alegria en sentir la veu de Crist quan ordena la resurrecció de Llàtzer:

\footnotetext{
com lo pare Adam e tots los altres qui eren en los lims, hoÿda la veu de sa gran senyoria e coneguda aquella, se eren alegrats de infinit goig, dient tots: «Làzer, per mercé, pus vos mana tornar al món, siau procurador de nosaltres, e com sereu davant sa magestat (...) que prestament vulla devallar a rompre lo carçre de la nostra longa e dura captivitat» (Villena 1497: CXXX)
}

El primer lloc on apareix la narració del davallament de Crist és als evangelis apòcrifs del segle IV (Minois 1994: 109 i s.); de fet aquest n'és un dels temes predilectes, i la tradició cristiana n'assumeix el contingut. Cal destacar-hi el de Nicodem (21-25), el que més desenvolupa aquest tema, seguit generalment a l'Edat Mitjana. El text recull el relat de Carí i Leuci, presents als llimbs al moment del davallament i després resuscitats amb Crist. Producte alexandrí, a l'evangeli de Nicodem conviuen l'infern cristià, representat per Satanàs, que coneix les profecies, i l'infern hel lenístic, personificat per Hades, que ignora qui és Crist i se sorprén de la seua arribada; tots dos mantenen un curiós debat. Mentre el seu cos encara penja a la creu, l'ànima del redemptor es presenta a les portes de l'infern, llavors se sent dins la veu que mana obrir-les; és un vers del salteri, de David, que Roís de Corella (1985: XXIII) tradueix: «Levau en alt les vostres portes, o prínceps, e levau-vos en alt vosaltres, portes eternals, hi entrarà lo rey de glòria». Hades, al contrari, les fa tancar; els patriarques criden, se sent la veu per segona volta, ara criden els àngels, la porta esclata esmicolada i Crist hi entra, il luminant tot l'espai. Amb gran espant dels diables, xafa la mort, encadena Satanàs i dóna la mà a Adam (moment que reflecteix la iconografia del davallament); els patriarques llavors 
Albert Toldrà i Vilardell. El més enllà en sant Vicent Ferrer, Francesc Eiximenis i sor Isabel de Villena. Els llimbs dels patriarques

(únicament s'esmenten els homes) s'agenollen i l'adoren. Després, tots plegats surten de l'infern entre cants de les profecies escaients, i Crist encomana els rescatats a sant Miquel, que els porta al paradís terrenal, en espera de l'ascensió.

En la Legenda Aurea, del s. XIII, Varazze (Vorágine 1982: 233) segueix Nicodem fil per randa; el conjunt dels diables substitueix l'Hades de Nicodem; en la versió catalana de les Vides de sants rosselloneses,

«Toletz les portes, prínceps, vostres, e levatz les portes perdurables, e entrarà lo Rey de Glòria». An aquesta vou corregren los demonis, e tancaren les portes de l'aram ab los forelats del ferre, e les clausiren (...) E adoncs lo Rey de Glòria sobrevenc, qui il luminà les tenebres perdurables, e estès la sua man, tenent la mà dreyta de Adam» (Varazze 1977: 383-387).

Sant Vicent, en diferents sermons, enfasitza aspectes contradictoris del davallament; en un lloc diu que s'hi manifestà obertament el poder diví: «volgué mostrar la sua grandesa en infern contra lo dyable, lligant-lo e trahent-ne los sants Pares» (Ferrer 1975, V: 227), però en un altre sembla insinuar el contrari: «volgué haver tanta humilitat que abans que pujàs als cels, devallà molt secretament en infern, en lo qual havie més de tantes mília ànimes» (Ferrer 1932, II: 256). En la seua narració del rescat, però, ja hi trobem les dones: «Los àngels vengueren primers: «Sus! Sus! Obrits les portes» (...) Pensau Adam e tots com deien: «Oh Senyor, redemptor tan desijat!» (...) Allí eren los innocents que féu matar lo rei Herodes; e venc l'ànima de santa Anna (...) e Josep (...) e venc l'ànima del lladre» (Ferrer 1973: 175).

Isabel de Villena (1497: CCXXXII) atorga, com hem vist ja, un gran protagonisme als presoners dels llimbs, sobretot a Adam i Eva; el plany de Maria pel seu fill resumeix el davallament i el rescat:

\footnotetext{
só molt certa que resuscitarà lo terçer dia aprés la sua mort, e serà lo dia de demà, qui és diumenge (...). com Jonàs stigué tres dies e tres nits en lo ventre de la Balena, axí staria en lo cor de la terra, ço és, en los lims de infern, per spay de tres dies e tres nits (...) aterrarà aquell príncep de infern, llevant-li tota la presa que tyrànnicament té de tots aquells singulars pares (...) e despullarà aquell lloc trencant e rompent les portes infernals.
}

El relat de la catàbasi en el Vita Christi és permenoritzat: ocupa els capítols CLXXXVII al CC; en destaquem el caràcter cerimonial i cortesà: Adam fa a Crist tres reverències, ell l'abraça, l'anomena «venerable pare», i mana als àngels portar-li una cadira; en aquell moment arriba als llimbs el bon lladre. Asseguts Crist i Adam, té lloc la desfilada de besamans dels presoners, que van prenen seient a mesura que saluden el salvador: sant Josep, sant Joaquim, Zacaries, Joan Baptista, Abraham, Moisès, «David ab tots los reys e sancts de Judea, e levant-se les corones del cap adoraren la majestat del Senyon», i els innocents, «vestits de blanch ab banderes en les mans». Acabada la processó masculina, els homes «feren una gran plaça, e meteren-se tots en orde per fer loch a les sanctes dones». Comencen Eva, del braç de sant Miquel, i santa Anna, del de sant Gabriel; segueixen Judith i Ester.

La pintura gòtica ha representat el drama amb un abundant programa iconogràfic força convencional. Crist dóna la mà a Adam, amb el banderí de l'Església triomfant i mostrant les cinc 
Albert Toldrà i Vilardell. El més enllà en sant Vicent Ferrer, Francesc Eiximenis i sor Isabel de

Villena. Els llimbs dels patriarques

nafres de la Passió, després de trencar les portes del recinte infernal, que jauen als seus peus, amb gran escampada de fragments metál lics. Els dimonis fugen de Crist espantats, fan gestos d'atac, desesperació o resignació, o espien els esdeveniments des d'un amagatall. Els patriarques surten de l'infern; si exhibeixen nimbus, és l'octogonal veterotestamentari. S'agenollen amb les mans juntes en actitud religiosa d'oració o en la gestualitat feudal del plet-homenatge, davant el seu senyor i salvador (Le Goff 1983: 333).

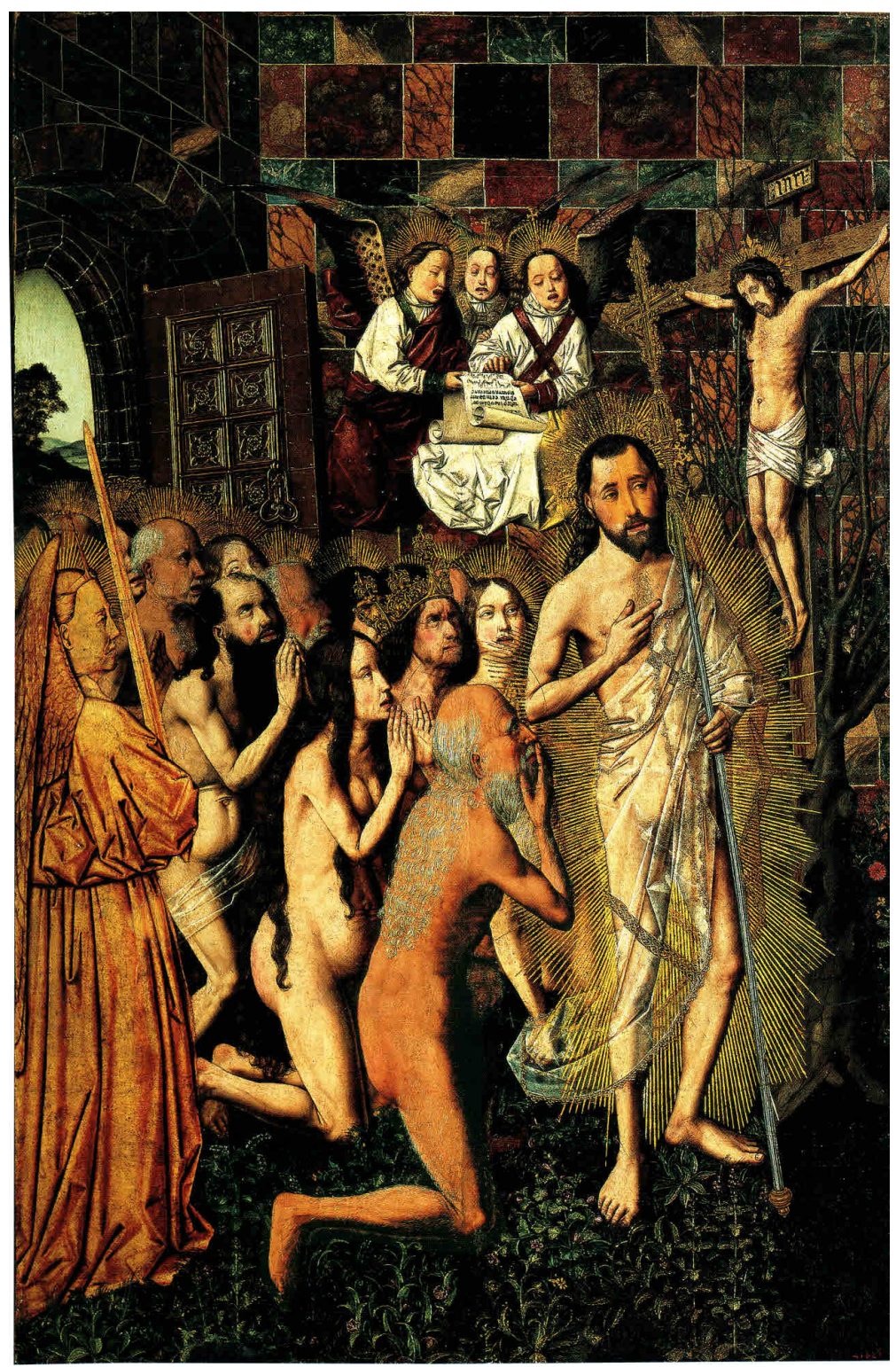

Bartolomé Bermejo, Visita de Crist resuscitat al Paradís (1475). Barcelona, Institut Amatller.

SCRIPTA, Revista internacional de literatura i cultura medieval i moderna, núm. 14/ desembre 2019/ pp. 175 - 188 ISSN: 2340-4841 · doi:10.7203/SCRIPTA.14.16364 
Albert Toldrà i Vilardell. El més enllà en sant Vicent Ferrer, Francesc Eiximenis i sor Isabel de Villena. Els llimbs dels patriarques

Aquesta composició iconogràfica és una herència romànica d'origen bizantí, amb afinitats amb el motiu clàssic -supervivència, diu Panofsky (1992: 27)- d'Hèrcules traient el Cerber de l'Hades. D’altra banda, Réau (1996: 53-59) indica que la imatge és el resultat de la fusió plàstica de dos moments narratius diferents, amb divers sentit dinàmic: descendent o catàbasi (entrada a l'infern $\mathrm{i}$ encadenament de Satanàs) i ascendent $\mathrm{o}$ anàbasi (rescat dels patriarques i sortida de l'infern).

Segueix cronològicament una escena surrealista, la visió pels patriarques de Crist a la creu, la qual juntament amb la visita a la mare de Déu, totes dues entre la mort i l'ascensió de Crist, són específicament catalanes, segons Yarza (1992: 161). No en tots els autors, per això; Roís de Corella, que en Lo quart del Cartoxà (1998: f.78 i 84) segueix més fidelment el text del Vita Christi de Ludolf de Saxònia, no n'inclou cap dels dos. El probable introductor n'és el Vita Christi d'Eiximenis, inspirat en el pseudo-Bonaventura. Al seu plantejament, Crist s'emporta miraculosament els patriarques, abans de resuscitar, al Calvari, per mostrar-los el seu cos a la creu: «d'equí pugà ab tota aquella santa companyia al munt de Caluari a instància dels sants pares per ensenyar lo seu cors penjat en la Creu, car encara no era leuat». ${ }^{8}$

Sant Vicent, diu Berg (1979: 304), seguiria ací Eiximenis. Però almenys al sermó del dia de pasqua de l'any 1413, predicat a València -manuscrit d'Aiora-, la versió és diferent: els presoners, impacients per la resurrecció, preguen a Crist que els deixe adorar el seu cos cum les naffres de la passió, però la visió té lloc en la resurrecció, al sepulcre, no abans ni a la creu del calvari. A l'alba de diumenge, Crist ordena: «Nunc exurgam. Et ideo sequemini me», i de sobte tota la multitud d'ànimes veterotestamentàries i àngels surt pel sepulcre darrere del salvador, l'ànima del qual es reintegra al seu cos, «anima sua intravit in corpore, et exivit gloriosus in corpore et in anima»; la terra tremola, i llavors patriarques i àngels adoren Crist, ara ja en cos i ànima, i entonen càntics de glòria (Ferrer 1995: 368-369).

En la dramatització de l'abadessa (Villena 1497: CCI-CCIII) la iniciativa és de les dones: «Oh, si podíem veure lo cos del Senyor nostre, qui encara penja en la creu!» Preguen a Eva que demane aquesta gràcia a Crist; ella cedeix l'honor a Adam, qui finalment s'adreça al messies: «Si plaïa a la Majestat vostra... tots los que ací som que poguéssem veure lo vostre excel lent cos, qui encara penja en la creu». Sor Isabel segueix ací Eiximenis, malgrat que ho planteja com una mera visió i no pas com un viatge miraculós: «E tantost fou fet un camí d’aquí on ells estaven fins a Monticalvari, e sens eixir d'aquell lloc los paregué ésser tots entorn de la creu e veure lo cos del Senyor molt clarament».

Bartolomé Bermejo (ca. 1435-ca. 1500), pintor andalús amb influències flamenques documentat a València entre 1465 i 1470 (Molina 1999: 119), seguirà aquesta narració d'Eiximenis i sobretot d'Isabel de Villena, al seu «Crist al paradís». ${ }^{9}$ L'ànima de Crist, en primer terme, assenyala el seu cos

8 Eiximenis, Vida de Jesuchrist, ms. 460, f. 221-222. Citat en Berg 1979: 305.

9 Barcelona, Institut Amatller d'Art Hispànic. Els altres tres quadres de la sèrie cristològica són a Barcelona, MNAC. Berg 1979: 304. Vegeu el que en diu Molina 1999: 137: «tal y como puso de relieve Berg, la traducción visual de los textos de las Vitae Christi medievales sirvió a Bermejo para llevar a cabo una compleja alegoría de la redención a través de una serie de cuatro tablas en las que se rememoran episodios posteriores a la Resurrección (...) Los especialistes coinciden en señalar que se trata de unas piezas realizadas

SCRIPTA, Revista internacional de literatura i cultura medieval i moderna, núm. 14/ desembre 2019/ pp. 175 - 188 ISSN: 2340-4841 · doi:10.7203/SCRIPTA.14.16364 
Albert Toldrà i Vilardell. El més enllà en sant Vicent Ferrer, Francesc Eiximenis i sor Isabel de

Villena. Els llimbs dels patriarques

a la creu, a la dreta; hi manquen la mare de Déu i el grup de la passió. A la vora, Adam, Eva, David, i darrere un possible Joan Baptista. Se situa l'escena en un àmbit tancat, al costat d'unes portes obertes i senceres, amb un àngel roig, amb espasa, damunt: obviament no es tracta dels llimbs. Berg (1979: 307) ubica l'escena al paradís terrenal, amb la identificació de la creu amb l'arbre del paradís, i per tant Crist com a fruita de l'arbre de la vida; l'única explicació per aquesta localització és la frase de Crist a la creu al bon lladre: «Hodie mecum eris in paradiso» (Lc 23, 43), avui seràs amb mi al paradís. Bermejo, doncs, varia el plantejament literari: ni el viatge real al Calvari d'Eiximenis, ni la visió des dels llimbs de sor Isabel.

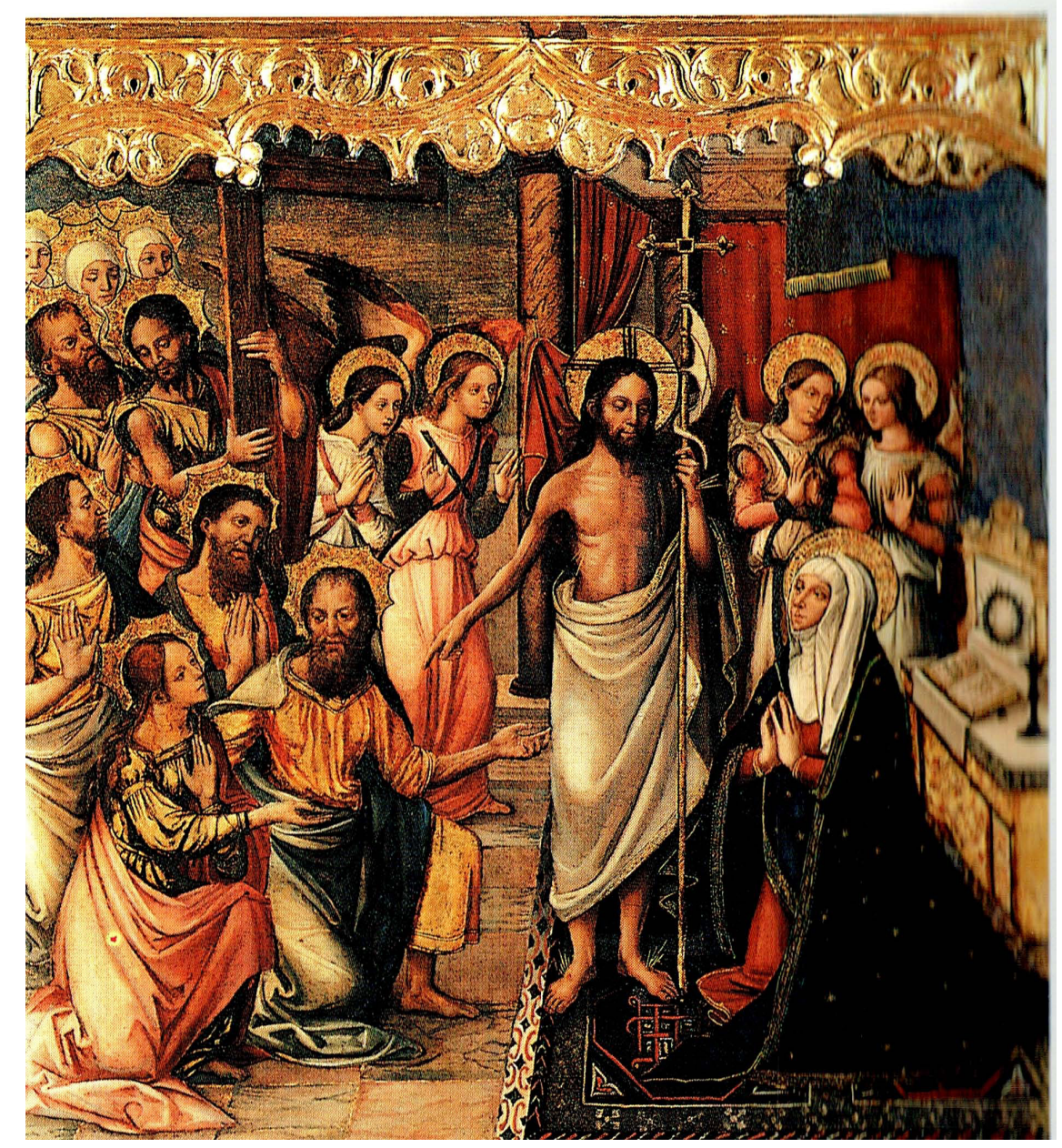

Vicent Macip, Visita a la mare de Déu, del retaule de sant Dionís i santa Margalida (principis s. XVI). València, Museu

Diocesà.

en Valencia durante la década de los 60. todas ellas nos ofrecen escenas o detalles iconogräficos bastante sorprendentes y que probablemente están inspirados en curiosos pasajes de carácter apócrifo recogidos en las obras de Francesc Eiximenis y Isabel de Villena, como es el caso del episodio de la entrada de Cristo en el Limbo».

SCRIPTA, Revista internacional de literatura i cultura medieval i moderna, núm. 14/ desembre 2019/ pp. 175 - 188 ISSN: 2340-4841 · doi:10.7203/SCRIPTA.14.16364 
Albert Toldrà i Vilardell. El més enllà en sant Vicent Ferrer, Francesc Eiximenis i sor Isabel de Villena. Els llimbs dels patriarques

Segueix l'altre episodi apòcrif específicament català: la salutació a la mare de Déu, amb els patriarques. Crist acabat de resuscitar, amb el àngels i les ànimes dels captius rescatats, es presenta a la cambra de la desconsolada Maria. Vegem la versió de sant Vicent; ell mateix ens en fa un resum: «apparech a la verge Maria mare sua (...) e volgué apparer no tot sols, mas ab aquella gran e innumerable companyia dels sants pares, los quals havia delliurats dels inferns» ${ }^{10}$.

En el sermó de la pasqua del 1413 a València en primer lloc Crist ofereix albixera a sant Gabriel per portar la nova a sa mare, en una repetició de l'anunciació ${ }^{11}$. Aplegats, i amb el Baptista com a mestre de cerimònies, tots reten honors a la mare de Déu, però ara comencen les dones, Eva la primera, amb aquesta paradoxa inicial: «O, filia mea, et mater $\rangle^{12}$. És ben significatiu aquest moment de trobada de les dues dones més importants de la religió cristiana: Eva, la pecadora fecunda, mare de la humanitat, i Maria, la santa verge-mare de Déu, que representen respectivament la caiguda i la redempció, una mena de versió femenina de la fusió de l'Antic i el Nou Testament, representada per la presència de Crist entre els patriarques dels llimbs.

En Isabel de Villena (1497, CCXXXVII-CCXXXIX) la narració és més detallada. Després del besamans, la processó torna a moure; sant Miquel obri la marxa amb la bandera de l'Església triomfant. Les ànimes dels patriarques, miraculosament, adopten una forma visible, «per consolació e delit de la senyora mare sua, la qual anava visitar». Es repeteix la missatgeria de sant Gabriel «a sa senyoria, de la qual era especial servidor e privat». En arribar, Crist i sa mare seuen en dues cadires portades per sant Miquel. Per si l'escena era poc extravagant, l'abadessa narra una disputa cortès entre Adam i sant Miquel per la preeminència en l’ordre de salutació: «O senyor príncep Miquel: no stigau en cortesies: anau vós primer, e tota la cavalleria vostra a fer reverència a la senyora Verge». Així comença una nova desfilada de besamans, ara a Maria, i després s’hi fa una festa, «grans dançes e goigs celestials ab aquella melodia angèlica dins la cambreta».

Trobem aquest motiu, sempre segons la versió de sor Isabel, en algunes pintures tardanes de l'àmbit català; a la de Francesc d'Osona, els patriarques, encapçalats ara per Eva, s'esperen al llindar mentre Crist saluda sa mare, i cinc àngels de colors diferents -representació de les diverses jerarquies- contemplen l'escena. A les dues versions de Vicent Macip, idèntiques, també Eva pren el protagonisme, situada davant per davant de la Verge. Crist presenta a sa mare Adam, qui al seu torn mostra la mare de Déu a Eva; aquesta allarga la mà cap a la Verge: representació conjunta dels dos homes fundadors -Adam i Crist-, i de les dues dones a ells vinculades i sotmeses: Eva i Maria. En la

10 Ferrer 1932, II: 258. En fa una altre resum en Ferrer 2006: 222: «communiter tenetur quod ante omnes Christus se demonstravit Virgini matri (...) premissus angelus nuntiat resurrectionem, dicendo: «Regina celi, letare» etc, et statim affuit Christus utique cum sanctis, quos de lymbo extraxerat, et multitudine angelorum».

11 Ferrer 1995 : 371: «Et Iesu ressucitato vocavit Gabrielem, et dixit quod lucraretur ipse les albixeres. Et iste festinanter ivit, et intravit cum magna claritate, et dixit: «Ave maria, gracia plena (...)». Statim veniet filius tuus».

12 Ferrer 1995: 371: «O, filia mea, et mater, per me fuit clausa porta paradisi, et per te cunctis credentibus generaliter est pateffacta»

SCRIPTA, Revista internacional de literatura i cultura medieval i moderna, núm. 14/ desembre 2019/ pp. 175 - 188 ISSN: 2340-4841 ·doi:10.7203/SCRIPTA.14.16364 
tardana versió de Joan de Joanes, Eva s'amaga emporuguida darrere Adam, qui és darrere de Crist, a qui el Baptista assenyala amb la mà. Un exemple de la desaparició d'aquest programa iconogràfic és la versió ${ }^{13}$ del pintor castellà Yáñez de la Almedina (1465-1536), per a la catedral de València: en la salutació de Crist resuscitat a sa mare, els patriarques s'han volatilitzat.

Pel que fa als llimbs, després del rescat i resurrecció, aquest espai romandrà ja buit per sempre, clausurat; no se'ns en torna a donar notícies. Sant Vicent diu que «romàs aquell lloc buit» (Ferrer 1973: 175); i Eiximenis (1992, IV: 55) «ara no sab hom que negú hi estiga». Tampoc no hi entra cap dels viatgers medievals al més enllà, com ara Dante (Inferno XXI, 106), que troba l'arc que hi condueix trencat pel terratrèmol que va provocar Crist en entrar-hi.

\section{Bibliografia}

\section{Textos}

San Agustín (2009) Confesiones, Madrid, Aguilar.

Denzinger-Schönmetzer (ed.) (1973) Enchiridion symbolorum definitionum et declarationum de rebus fidei et morum, Barcelona, Herder.

Ferrer, V. / Sanchis Sivera, J. (ed.) (1932) Sermons (I-II) i Schib, G. (ed.) (1975) (III-VI), Barcelona, Barcino, 6 vol.

__./ Sanchis Guarner (ed.) (1973) Sermons de Quaresma, València, Albatros, 2 vol.

/ Robles Sierra, A. (ed.) (1995) Colección de sermones de cuaresma y otros según el manuscrito de Ayora, València, Ajuntament de València.

. / Gimeno Blay, F. I Mandingorra Llavata, M. L. (eds.) (2002) Sermonario del Real colegio Seminario del Corpus Christi de Valencia, València, Ajuntament de València.

—. / Gimeno Blay, F. I Mandingorra Llavata, M. L. (eds.) (2006) Sermonario de Perugia (Convento dei Domenicani, ms. 477), València, Ajuntament de València.

13 València, MBA (ca. 1515) 
Albert Toldrà i Vilardell. El més enllà en sant Vicent Ferrer, Francesc Eiximenis i sor Isabel de Villena. Els llimbs dels patriarques

Dante, A. / Cataldi, P. i Luperini, R. (eds.) (1989) La Divina commedia, Florència, Le Monnier.

Eiximenis, F. (1992) Libre dels àngels, tesi doctoral inèdita de Gascón Uris, S., Barcelona, Departament de Filologia Catalana de la Universitat Autònoma de Barcelona.

Llull, R. / Casassas, O. (ed.) (1981) Libre de doctrina pueril, Palma, Imagen 70.

Roís de Corella, J. / López, J. A. i Ribes, V. (eds.) (1985) Psalteri, Barcelona, Conselleria de Cultura, Educació i Ciència de la Generalitat Valenciana / Revista Saó / Abadia de Montserrat.

—. (1998) Lo quart del Cartoxà, Ajuntament de València (facsímil).

Santos Otero, A. (ed.) (1999) Los Evangelios Apócrifos, Madrid, Editorial Católica.

Tomas d'Aquino (1961-1965) Summa Theologiae, Madrid, Editorial Católica, 5 vol.

Varazze, I. / Kniazzeh, C. H. S. M. i Neugard, J. (eds.) (1977) Vides de sants rosselloneses, Barcelona, Fundació Salvador Vives Casajoana.

Villena, I. / Hauf, A. (ed.) (2006) Vita Christi, València, Biblioteca Valenciana.

Vorágine, S. (1982) La leyenda dorada, Madrid, Alianza, 2 vol.

\section{Estudis}

Amat, J. (1985) Songes et visions. L'au-delà dans la littérature latine tardive, París, Études Augustiniennes.

Baschet, J. (2000) Le sein du père. Abraham et la paternité dans l'Occident médiéval, París, Gallimard.

Berg Sobré, J. (1979) «Eiximenis, Isabel de Villena and some fifteenth century illustrations of their works», dins Estudis de llengua, literatura i cultura catalana. Actes del primer col loqui d'estudis catalans a Nordamèrica, Abadia de Montserrat.

Bologne, J. C. (1993) Du flambeau au bûcher. Magie et superstition au Moyen Âge, París, Plon.

Bot, J. M. (2002) Osons reparler de l'Enfer, París, Éditions de l'Emmanuel.

Brown, P. (1997) «Vers la naissance du purgatoire. Amnistie et penitence dans le christianisme occidental de l'Antiquité tardive au Haut Moyen Age», Annales, HSS, n 52, pp. 1247-1274.

Delumeau, J. (1992) Une histoire du Paradis. Le Jardin des délices, París, Fayard.

Durand, G. (1963) Les structures anthropologiques de l'imaginaire, París, PUF.

Eliade, M. (1999) Lo sagrada y lo profano, Barcelona, Paidós.

(1948-1959) Enclopedia Cattolica, Ciutat del Vaticà, Ente per l'Enciclopedia Cattolica e per il Libro Cattolico. 
Albert Toldrà i Vilardell. El més enllà en sant Vicent Ferrer, Francesc Eiximenis i sor Isabel de Villena. Els llimbs dels patriarques

Hauf i Valls, A. (1995) «Profetisme, cultura literària i espiritualitat en la València del segle XV: d'Eiximenis i sant Vicent Ferrer a Savonarola, passant pel Tirant lo Blanc», dins Xàtiva, els Borja: una projecció europea. Catàleg de l'exposició, Xàtiva, Ajuntament de Xàtiva.

—. (1996) «Text i context de l'obra de sor Isabel de Villena», dins Literatura valenciana del segle XV. Joanot Martorell i sor Isabel de Villena. València, Consell Valencià de Cultura.

Le Goff, J. (1981) El nacimiento del Purgatorio, Madrid, Taurus.

(1983) Tiempo, trabajo y cultura en el Occidente Medieval, Madrid, Taurus.

Maldonado, L. (2003) «La religiosidad popular», dins La religiosidad popular I. Antropología e Historia, Barcelona, Anthropos, pp. 30-43.

Martínez Romero, T. (2002) Aproximació als sermons de sant Vicent Ferrer, Paiporta, Denes.

Minois, G. (1994) Historia de los infiernos, Barcelona, Paidós.

Molina i Figueras, J. (1997) «Modos y fórmulas de traducción visual de la Leyenda Áurea en la pintura gótica catalana», Boletín del Museo e Instituto «Camón Azৃnar», LXX 1, pp. 261-300.

- (1999) Arte, devoción y poder en la pintura tardogótica catalana, Universidad de Murcia.

Panofsky, E. (1992) Estudios sobre iconología, Madrid, Alianza.

Polo de Beaulieu, M. A. (1998) «De Beaucaire (1211) a Alès (1323), les revenants et leurs révélations sur l'au-delà», dins La mort et l'au-delà en France meridionale (XIIe-XVe siècle), Toulouse, Privat.

Portús, J. (2004) «Infiernos pintados: iconografía infernal en la Edad Moderna hispánica», dins Tausiet M. i Amelang J. S. (eds.), El diablo en la Edad Moderna, Madrid, Marcial Pons.

Pozo, C. (1980) Teología del Más Allá, Madrid, Editorial Católica.

Réau, L. (1996) Iconografía del arte cristiano. Iconografía de la Bíblia, Barcelona, Serbal, 2 vol.

Robles Sierra, A. (1996) Obras y escritos de san Vicente Ferrer, València, Ajuntament de València.

Rodríguez Barral, P. (2004) «Purgatorio y culto a los santos en la plástica catalana bajomedieval», Locvs Amoenvs, 7, pp. 35-51.

Rubio Tovar, J. (2002) «El viaje de Dante por los cielos», dins Beltran R. (ed.) Maravillas, peregrinaciones y utopias: literatura de viajes en el mundo románico, Universitat de València.

Sanchis Guarner, M. (1991) «Política i societat a la València medieval: Francesc Eiximenis», dins La Corona d'A Aragó. el regne de València en l'expansió mediterrània (1238-1492), València, Corts Valencianes.

Toldrà i Vilardell, A. (2000) Aprés la mort. Un viatge amb sant Vicent al més enllà medieval, València, 3 i 4.

—_. (2010) Mestre Vicent ho diu per espantar. El més enllà medieval, Catarroja, Afers.

—. (2015) Paraula i passió. Sant Vicent Ferrer, predicador, Picanya, El Bullent.

Yarza Luaces, J. (1992) Baja Edad Media. Los siglos del gótico, Madrid, Sílex.

SCRIPTA, Revista internacional de literatura i cultura medieval i moderna, núm. 14/ desembre 2019/ pp. 175 - 188 